Faculdade de Ciências Econômicas UFRGS
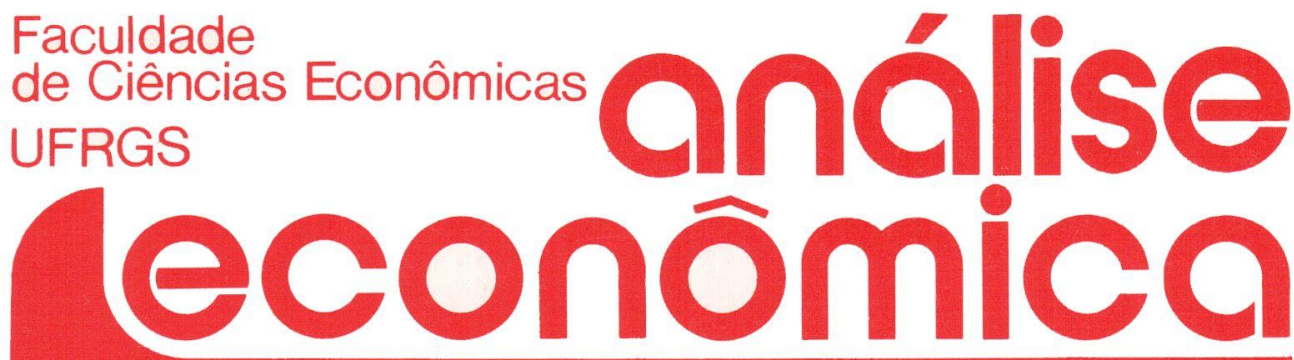

- apResentaÇ̃o à "ANálise simples da MAXIMIZAÇÂO DO BEM-ESTAR" DE FRANCIS BATOR

João Rogério Sanson

- UMA ANÁlise SIMPLES da MAXIMIZAÇÃo do BEM-ESTAR

Francis M. Bator

- O Regime de câmbio flutuante numa ETAPA DE TRANSICÃO

Francisco Eduardo Pires de Souza

- AgREgAdos monetÁRIOS, NIVEL DE RENDDA NOMINAL, TAXA DE INFLAÇÃO: UMA ANÁLISE DA CAUSALIDADE NO BRASIL, 1972 A 1987

Divanildo Triches

- A EXPlosão de CONSUMO do CRUzAdo Marcelo Cortes Neri

- METOdologia de PLANEJAMENTO do SETOR ELÉTRICO: QUESTŐES DOS ANOS 90

João Lizarolo de Araújo

Adilson de Oliveira

- CONCENTRAÇÃo INDUSTRIAL NO BRASIL SEGUNDO OS CENSOS, 1907-1980

Olimpio J. de Arrouxelas Galvão

- O VAlor, A RIQUEza e A TEORIA DE SMITH Reinaldo A. Carcanholo

- O "ESTADO ESTACIONÁRIO" e A ECONOMIa CLÁSSICA

Gentil Corazza

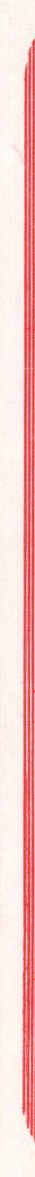
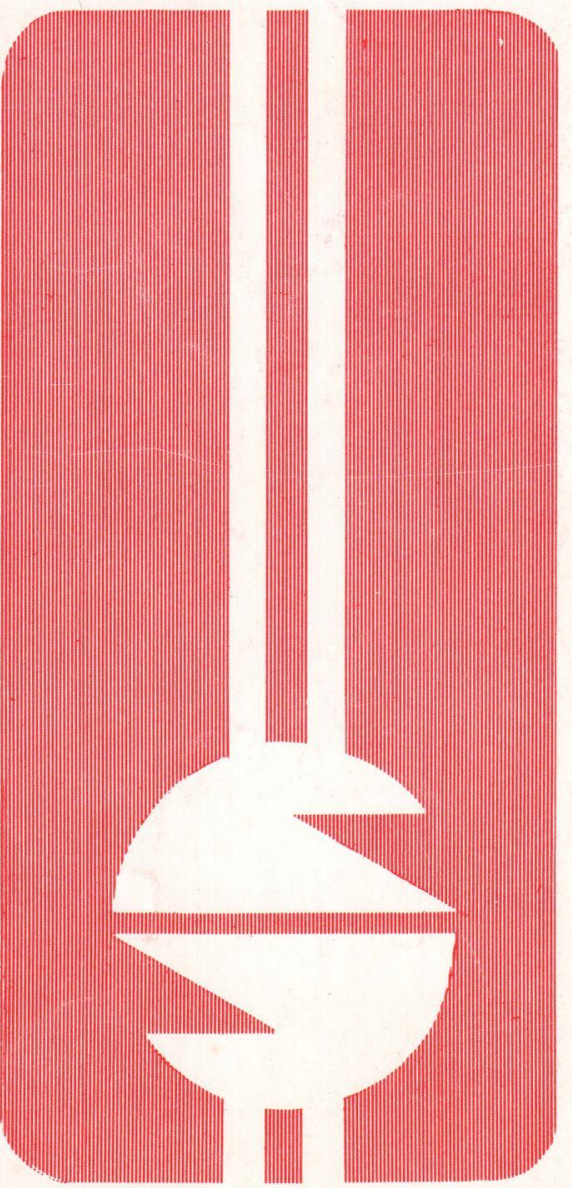
UNIVERSIDADE FEDERAL DO RIO GRANDE DO SUL

Reitor: Prof Tuiskon Dick

FACULDADE DE CIÊNCIAS ECONÔMICAS

Diretora: Prof ${ }^{\text {a }}$ Yeda Rorato Crusius

CENTRO DE ESTUDOS E PESQUISAS ECONÔMICAS

Diretor: Reinaldo Ignacio Adams

DEPARTAMENTO DE CIÊNCIAS ECONÔMICAS

Chefe: Prof. Pedro Cezar Dutra Fonseca

CURSO DE PÓS-GRADUAÇĀO EM ECONÔMIA

Coordenador: Prof. Nali de Jesus de Souza

CURSO DE PÓS-GRADUAÇĀO EM ECONOMIA RURAL

Coordenador: Prof. Atos Freitas Grawunder

CONSELHO EDITORIAL: Achyles Barcelos da Costa, Aray Miguel Feldens, Atos Freitas Grawunder, Carlos Augusto Crusius, Ernani Hickmann, João Rogério Sanson, Juvir Luiz Mattuella, Maria Imilda da Costa e Silva, Nali de Jesus de Souza, Nuno Renan Lopes de Figueiredo Pinto, Otilia Beatriz Kroeff Carrion, Otto Guilherme Konzen, Paulo Alexandre Spohr, Pedro Cezar Dutra Fonseca, Reinaldo Ignacio Adams, Roberto Camps Moraes, Valter José Stülp, Yeda Rorato Crusius, David Garlow (Wharton Econometrics Forecasts Association, E.U.A.), Edgar Augusto Lanzer (UFSC), Eleutério F. S. Prado (USP), Fernando Holanda Barbosa (FGV/RJ), Gustavo Franco (PUC/RJ), Joaquim Pinto de Andrade (UNB), Juan H. Moldau (USP), Werner Baer (Univ. de Illinois, E.U.A.)

COMISSÃO EDITORIAL: Atos Freitas Grawunder, Pedro Cezar Dutra Fonseca, Reinaldo Ignacio Adams e Roberto Camps Moraes.

EDITOR: Nali de Jesus de Souza

SECRETARIA: Maria Ivone de Mello (normalização), Vanete Ricacheski (revisão de textos), Zélide Bregalda (Secretária)

FUNDADOR: Prof. Antônio Carlos Santos Rosa

Os materiais publicados na revista Análise Econômica são de exclusiva responsabilidade dos autores. $\dot{E}$ permitida a reprodução total ou parcial dos trabalhos, desde que seja citada a fonte.

Aceita-se permuta com revista congêneres. Aceitam-se, também, livros para divulgação, elaboração de resenhas ou recensões.

Toda correspondência, material para publicaçāo (vide normas na $3^{\mathrm{a}}$ capa), assinaturas e permutas devem ser dirigidos ao seguinte destinatário:

PROF. NALI DE JESUS DE SOUZA

Revista Análise Econômica

Av. João Pessoa, 52

90.040 - PORTO ALEGRE (RS), BRASIL

Telefones: (0512) 28.1633; 24.6022; 26.0012 - Ramals 3440 e 3507

FAX: (0512) 25.5253 


\title{
APRESENTAÇÃO À “'ANÁLISE SIMPLES DA MAXIMIZAÇÃO DO BEM-ESTAR" DE FRANCIS BATOR
}

\author{
João Rogério Sanson*
}

No ensino de Microeconomia, em nível de graduação e no primeiro semestre da pós-graduação, um ponto muitas vezes difícil de ser transmitido aos alunos é a teoria do bem-estar. É quando muitos professores ficam até desmotivados. Pois é nessa área que o artigo de Bator tornouse um clássico didático. Trata-se de uma tentativa de mostrar, num artigo só, a natureza do que se discute sob o rótulo de "bem-estar" em Economia, atendo-se à simplicidade da apresentação geométrica e dos argumentos intuitivos, com um mínimo de expressōes algébricas.

É um artigo de 1957. Contudo, a prova de sua vitalidade é que ós livros de microeconomia para a graduação ainda continuam apresentando resumos dele em suas discussōes sobre bem-estar. Além disso, muitos de seus tópicos são bastante relevantes para as discussões correntes sobre socialismo versus capitalismo, ou sobre distribuição de renda monetária versus distribuição de propriedade, ou sobre "preços-sombra" para análise de projetos.

Em resumo, o objetivo do artigo é perguntar-se sobre qual deveria ser a alocação de recursos entre os bens e a distribuição desses bens entre os indivíduos com vistas a obter-se uma distribuição de renda real pré-determinada para os indivíduos dessa sociedade. A renda real é definida como uma posição no mapa de preferências. Além disso, essa distribuição de renda real presume que nenhuma oportunidade de se ob* Professor do Departamento de Economia e do Curso de Pós-Graduação em Economia da
UFRGS

\begin{tabular}{|l|l|l|l|l|}
\hline ANÅLISE ECONÔMICA & ANO 9 & NNo 15 & MARÇO/91 & p.5-8 \\
\hline
\end{tabular}


ter renda real seja desperdiçada. Em seguida, pergunta-se como tal resultado poderia ser obtido sob diferentes arranjos institucionais. Embora a discussão das seções 2 e 3 privilegie os mercados "reais" perfeitamente competitivos, ali mesmo o leitor pode tomar conhecimento dos burocratas de Lange-Lerner, numa espécie de socialismo "real" com planejamento perfeito. As três seções seguintes discutem, sempre de forma facilitada, extensões ao modelo básico. É nestas seções que se encontram discussões mais detalhadas dos limites dos mercados perfeitos e do planejamento perfeito como instrumentos institucionais para se obter a distribuição de renda real politicamente determinada. Nas notas sobre a literatura, ao final do artigo, o leitor poderá encontrar as referências básicas sobre tal discussão. Tais referências são pontos iniciais úteis para se compreender os problemas de incentivo sob os regimes estatistas.

Contudo, o uso do artigo de Bator como base para os livros de microeconomia para a graduação gerou um erro de interpretação muito grave. Trata-se da interpretação da análise de Bator, das caixas de Edgeworth para produção e consumo, como teoria do equilibrio geral. $\dot{E}$ erro comum a "best-sellers" como Ferguson, Bilas e Miller. Infelizmente, apenas alguns textos que não se tornaram populares evitaram esse erro. É o exemplo de Lancaster. O que Bator faz não é análise de equilibrio geral: ele faz maximizaçāo condicionada, auxiliado por instrumentos geométricos, evitando o uso do cálculo.

$\mathrm{O}$ uso de princípios de dualidade e a maior abertura da Economia para a Sociologia e a Ciência Política nas décadas recentes certamente tornaram algumas questōes discutidas no artigo um pouco desatualizadas. Hoje se inclui no cálculo dos "preços-sombra" efeitos redistributivos. Além disso, há a proposição de Thurow de que a mudança na distribuição de renda $\hat{e}$ um bem público, o que praticamente tira de cena a função social de bem-estar. Isto tudo sem contar toda a discussão da escolha pública e da teoria da concorrência entre partidos políticos. Assim, este artigo deve ser visto como uma introdução de caráter didático às questōes ali levantadas. Discussões mais atualizadas podem ser encontradas em livros didáticos mais novos, especialmente aqueles voltados para análise de custo-benefício e economia do setor público. De qualquer modo, o leitor familiarizado com os periódicos Journal of Economic Literature, Literatura Econômica e Social Sciences Citation Index pode atualizar facilmente a sua bibliografia.

Há duas referências a nomes no artigo que hoje estão fora do con- 
texto. A primeira está na nota de rodapé no 13. Ali, ao referir-se aos burocratas do tipo Lange-Lerner, diz-se que eles devem "tomar os preços como dados e maximizar ou Sibéria". A referência a uma região cara a Stalin é uma gozação do ambiente da guerra fria dos anos cinqüenta. $\mathrm{Na}$ verdade, os burocratas imaginados pelos teóricos do planejamento perfeito maximizariam lucros porque sua remuneração seria proporcional aos lucros das empresas administradas por eles.

A outra referência ocorre na subseção 1.3 e nota de rodapé no 8 . Ao dizer que a função social de bem-estar decorre do processo político e que existe uma infinidade de especificações para ela, Bator diz que a função poderia ser a de Mossadegh, embora ela "provavelmente não seja transitiva". Mossadegh foi um político de longa carreira no Irā. Ele se tornou primeiro-ministro no meio de um movimento que nacionalizou uma empresa petrolífera, cuja propriedade era quase toda inglesa. Foi ministro de 1951 a 1953, sendo deposto, julgado e preso por três anos. É claro que o exemplo de Bator está influenciado pela imprensa internacional da época que transformou o nome de Mossadegh numa palavra de uso comum.

Contudo, em favor do artigo está justamente a discussão dos vários arranjos institucionais que são possiveis para se atingir o ótimo de bem-estar. Numa época em que o macarthismo ainda tinha sua influência no meio acadêmico e a guerra fria estava em andamento, foi no minimo audaz tal discussão num artigo de divulgação teórica para um público amplo, constituído de economistas não-matemáticos e estudantes de graduação.

A tradução para o português, apresentada a seguir, envolveu uma pequena adaptação que deve ser mencionada aqui. Os dois bens são ameixas e nozes na tradução, em vez de maçãs e nozes, como no original. Buscou-se preservar as letras das variáveis no texto e nos gráficos. Essas letras foram definidas por Bator de forma mnemônica. 


\section{BIBLIOGRAFIA}

BILAS, Richard A. Teoria Microeconómica. Rio de Janeiro: Forense, 1970.

FERGUSON, C.E. Teoria Microeconômica. Rio de Janeiro: Forense, 1981.

LANCASTER, Kelvin. Teoria Microeconômica. Rio de Janeiro: Forum, 1969.

MILLER, Roger L. Microeconomia. São Paulo: McGraw-Hill do Brasil, 1981.

THUROW, Lester. The Income Distribution as a Pure Public Good. Quarterly Journal of Economics. v.85, n.5, p.327-136, May 1971. 